\title{
4 Genetic diversity and population structure among goat genotypes in Kenya
}

7 Ruth W. Waineina ${ }^{12^{*}}$, Kiplangat Ngeno ${ }^{1 \pi}$, Tobias O. Otieno ${ }^{1 \%}$ and Evans D. Ilatsia ${ }^{2 \pi}$

$10{ }^{1}$ Department of Animal Sciences, Animal Breeding and Genomics Group, Egerton University,

11 Njoro, Kenya

12 2Dairy Research Institute, Kenya Agricultural \& Livestock Organization, Naivasha, Kenya 
21 Population structure and relationship information among goats is critical for genetic improvement,

22 utilization and conservation. This study explored population structure and level of gene

23 intermixing among four goat genotypes in Kenya: Alpine $(\mathrm{n}=30)$, Toggenburg $(\mathrm{n}=28)$, Saanen

$24(\mathrm{n}=24)$ and Galla $(\mathrm{n}=12)$. The population structuring and relatedness were estimated using

25 principal component analysis utilizing allele frequencies of the SNP markers. Genotype

26 relationships were evaluated based on the calculated Reynolds genetic distances. A phylogenetic

27 tree was constructed to represent genotype clustering using iTOL software. Population structure

28 was investigated using model-based clustering (ADMIXTURE) Genotypes relationships revealed

29 four distinctive clusters: Alpine, Galla, Saanen and Toggenburg. The ADMIXTURE results

30 revealed some level of gene intermixing among Alpine, Toggenburg and Saanen with Galla.

31 Saanen goats were the most admixed genotype with $84 \%, 7 \%$ and $4 \%$ of its genome derived from

32 Galla, Alpine and Toggenburg respectively. Alpine and Toggenburg goats shared some associations with the Galla goat; $10 \%$ and $1 \%$ respectively. The association of Galla with other genotypes was anticipated since Galla goat was used as the founder population for crossbreeding

35 with Saanen, Alpine and Toggenburg breed. The genetic variations among the goat genotypes observed, will provide a good opportunity for sustainable utilization, conservation and future

37 genetic resource improvement programs in goat genotypes in Kenya. 
42 Goats are known to be the most adaptable and widespread across various geographical conditions,

43 ranging from the mountains to the deserts and tropics of Africa. The roles of goats in supporting

44 rural household economies in developing countries are well documented [1-3]. They form

45 important sources of food and nutritional security through the supply of milk and meat, income generation through sale of surplus stock and insurance against unforeseen risks and other non-

47 tangible cultural values [4-6]. Recent studies have shown that goats farming is one of the alternative climate-smart agricultural practices that could build farmers resilience to climate change-related challenges [7]. The diminishing land sizes in the medium to high potential areas due to human population pressure, expansion of urban areas and climate change-related challenges are triggers to alternative farming practices such as intensive dairy goat production [8]. This is

52 because dairy goat production offers more multi-functionality, flexibility and adaptability to varied 53 production conditions.

54 In Kenya, dairy goat production has mainly been supported by exotic breeds (Toggenburg, Anglo-

55 Nubian, German Alpines, Saanen and Boer) and their crosses with selected local breeds (Galla and small East African goat) [9-11]. The exotic breeds were introduced to various parts of the country

57 by the Government of Kenya (GoK) and Non-Governmental Organizations (NGOs). The ultimate

58 aim has been to increase their productivity through appropriate husbandry and disease 59 interventions [12] and targeted breeding strategies such as crossbreeding $[12,13]$.

60 Crossbreeding has been the breeding strategy of choice to improve the productivity of goats under 61 various production systems $[12,14]$. This has resulted in an increase in population sizes of 62 crossbred goats especially in the target projects areas and other areas apart from the original entry 
63 points in the country $[12,15]$. However, the increase in population sizes did not necessarily correspond to enhanced productivity but rather reflected the many numbers of households who were striving to support their livelihoods through goat farming [15-17].

66 There was limited technical capacity on the farmers' side on how to manage the rather complex 67 crossbreeding programs, a fact that could have had a bearing on the sustainability of such initiatives 68 in the long term [15-17]. The net result of this has been the un-systematic crossing of the existing 69 poulation, poor flock management, lack of records to support decision making and generally lack 70 of simplified breeding programs to guide in genetic improvement of goats in the country [18].

71 Currently, admixtures of exotic and local goats are reared as dairy goats in different parts of the 72 country under different production systems. There is a huge source of genetic diversity in the 73 current goat populations in Kenya. This is as a result of unsystematic crossbreeding and lack of 74 records keeping by most of the smallholder farmers. This calls for the need to characterize, 75 conserve and utilize sustainably under various production systems. It is important to determine 76 genetic diversity in populations because it provides the basis for natural and artificial selection $77[19]$.

78 To measure and describe genetic diversity in the animal genetic resource, phenotypic and 79 molecular characterization tools are used as a starting point to understand the animal resources and 80 make use of them sustainably [20]. This includes all information on breed origin, development, 81 structure, population, quantitative and qualitative characteristics in defined management and 82 climatic conditions $[21,22]$.

83 Molecular characterization using genetic markers are powerful tools which can be realised in many 84 applications in a breeding program. For instance, it can be used to characterize the genetic 
85 variability within and genetic distance between breed populations, genomic selection, parentage verification and genetic diversity preservation $[23,24]$. This can be done by using categories of

87 genetic markers to detect polymorphism in nuclear DNA.

88 Microsatellite and single-nucleotide polymorphisms [SNPs] are the most commonly used markers

89 in animal breeding related fields [25]. Microsatellite, however, has limitations in genetic diversity 90 which includes; null alleles [24], homoplasy [26, 27] and linkage disequilibrium [28]. SNP several

91 advantages relative to Microsatellite, among others, SNP is highly reproducible and very

92 informative [29] and markers can represent either neutral or functional genetic diversity [30].

93 GoatSNP50 Bead Chip (Illumina, Inc. San Diego, CA 92122 USA) which was developed from

94 SNP loci detected by whole-genome sequencing of six different goat breeds according to Tosser-

95 Kloppet et al [31] is available. This has made SNPs markers to be the most popular and advanced

96 technology in molecular breed characterization in goats. Additionally, its robustness, low

97 genotyping costs, automatic allele calling and capability to interrogate the goat genome at high resolution [32] demonstrate practicability to implement genomic characterization in goats. admixture among the goat genotype populations by use of SNPs makers. This study, therefore, investigated genetic diversity, population structure and admixture among goat genotypes in Kenya.

102 The results from this study will provide information which can be used in facilitating management 103 efforts in conserving and utilizing the various goat genetic resources sustainably. 


\section{Study area} kept by the farmer group in the said County of study. To ensure the representativeness of sampling,

124 for each breed, unrelated animals were selected from various farms across the designated Counties. 
125 The Galla goat breed, however, did not follow the criteria because they were from the Government breeding station where record keeping was used to avoid sampling related animals.

127 A total of 96 animals including three exotic genotypes $($ Toggenburg $=30)($ Alpine $=28),($ Saanen

$128=24)$ and one indigenous $($ Galla $=12)$ goats were incorporate in this study. The Toggenburg and

129 Alpine were found in Eastern and Central Kenya under Meru Goat Breeders Association (MGBA)

130 and Dairy Goat Association of Kenya (DGAK), respectively. Saanen goats were found in Homa-

131 Bay. Galla goats were sampled from sheep and goat Government station in Naivasha.

132 Whole blood $(10 \mathrm{ml})$ was collected from the jugular vein into Vacutainer tubes with 133 Ethylenediaminetetraacetic acid (EDTA) as an anticoagulant. The blood was stored at $-20^{\circ} \mathrm{C}$ for 134 two months before genomic DNA extraction. The procedure of blood sampling followed [33] 135 guidelines. To allow for possible loses, mistyping and missing values, two adult does per 136 household was sampled. From each animal, a duplicate was collected and kept separately during 137 transportation and storage. For each sample, the following information was collected: sex of the 138 animal, basic pedigree information, size of the flock, breed, any relevant phenotypic feature and a 139 photograph of the goat.

140 The study was conducted in strict accordance with the recommendations for the Institute of 141 Primate Research (IPR) ethical guidelines on animal care and use of laboratory animals and also 142 for the collaborating organizations. The protocol was approved by the committee on the ethics of 143 Animal Experiments of the University of Egerton in Kenya. A qualified veterinary officer 144 collected the whole blood following FAO (2011) guidelines to reduce pain and discomfort to a 145 minimum. 
148 Genomic DNA was extracted from the whole blood using the DNeasy Blood and tissue kit

149 (Qiagen ${ }^{\circledR}$, Hilden, Germany). Genomic DNA was quantified using Nanodrop Spectrophotometer

150 (Nanodrop ND-1000) and genotyped using the GoatSNP50 Bead Chip (Illumina, Inc. San Diego,

154 The following filtering was applied to raw reads; SNPs with less than $95 \%$ call rate, less than 0.05

155 Minor Allele Frequency (MAF), Hardy Weinberg Equilibrium (HWE) $\mathrm{P}<0.001$ and more than

$15610 \%$ missing genotypes were filtered using Plink v1.9 [34]. Genetic diversity basic indices which

157 include the proportion of polymorphic markers $\left(\mathrm{P}_{\mathrm{N}}\right)$ inbreeding coefficient, observed and expected

158 heterozygosity were calculated within genotypes using PLINK [34]. The population structuring 159 and relatedness were estimated by principal components analysis (PCA) from the R package SNPRELATE [35]. Besides, the population structure was investigated using model-based clustering ADMIXTURE 1.3.0 software [36]. This helped to deduce the true number of genetic 
169 Quality control procedure on the 53,347 SNPs included in the SNP chip excluded a total of 3,542

170 SNPs retaining 9,805 SNPs for downstream analysis (Table 1). Out of the SNPs excluded, 2235

171 as a result of less than 0.1 missing per SNP. About 663 SNPs significantly deviated from HWE (P

$172<0.001)$ and 644 had MAFs less than 0.05. Galla genotype showed the highest number of SNPs

173 excluded in total $(0,688)$, whereas Alpine revealed the lowest number of SNPs excluded $(5,129)$.

174 Table 1. Goat genotype, number of goats, number of exclude and remaining SNPs and

175 number of goats

\begin{tabular}{|c|c|c|c|c|c|c|c|c|}
\hline \multirow{3}{*}{ Genotype } & \multirow{3}{*}{$\mathrm{N}$} & \multicolumn{5}{|c|}{ Excluded SNPs } & \multirow{3}{*}{$\begin{array}{l}\text { Remaining } \\
\text { SNPs }\end{array}$} & \multirow{3}{*}{$\begin{array}{l}\text { Remaining } \\
\text { samples }\end{array}$} \\
\hline & & & & & & & & \\
\hline & & MIND & GENO & HWE & MAF & Total & & \\
\hline Saanen & 24 & 0 & 2453 & 38 & 3658 & 6149 & 47198 & 24 \\
\hline Alpine & 29 & 1 & 2496 & 47 & 2586 & 5129 & 48218 & 28 \\
\hline Galla & 12 & 0 & 2413 & 26 & 8249 & 10688 & 42659 & 12 \\
\hline Toggenburg & 31 & 1 & 2345 & 50 & 4690 & 7085 & 46262 & 30 \\
\hline Merged & 96 & 2 & 2235 & 663 & 644 & 3542 & 49805 & 94 \\
\hline
\end{tabular}

$176 \mathrm{~N}$, number of animals; MIND, genotype missing $(<0.1)$, GENO, SNP missing $(<0.15)$, MAF,

177 minor allele frequency; HWE, Hardy-Weinberg equilibrium (P-value $<0.001)$. 
The four indices (polymorphic SNPs, mean allele frequency, observed and expected heterozygosity and inbreeding coefficient) of genetic diversity were calculated within each genotype (Table 2). The assessment of the proportion of SNPs that exhibited both alleles within SNPs ranged from $94 \%$ to $80.7 \%$. The highest values of polymorphic were observed in Alpine (94.6\%) and Saanen (92.2\%) and both were involved in SNP chip discovery panel. The lowest proportion of polymorphic loci $\left(\mathrm{P}_{\mathrm{N}}\right)$ was detected in Galla genotype (80.7\%). Across all the loci, the lowest MAFs was found in Galla (0.291) and highest in Alpine (0.323).

Table 2. Proportion of polymorphic SNPs $\left(P_{N}\right)$ mean allele frequency $(\mathrm{MAF})$, Observed $\left(H_{o}\right)$

and expected $\left(H_{e}\right)$ heterozygosity and inbreeding coefficient (F)for the goat genotypes.

\begin{tabular}{lcccccc}
\hline Genotype & $\mathbf{N}$ & $\mathbf{P}_{\mathrm{N}}$ & $\mathbf{M A F}$ & $\mathbf{H}_{\mathbf{0}} \pm \mathbf{S D}$ & $\mathbf{H}_{\mathbf{e}} \pm \mathbf{S D}$ & $\mathbf{F}$ \\
\hline Toggenburg & 30 & 89.900 & 0.297 & $0.580 \pm 0.032$ & $0.580 \pm 0.001$ & -0.013 \\
Alpine & 28 & 94.600 & 0.323 & $0.558 \pm 0.026$ & $0.564 \pm 0.001$ & -0.015 \\
Galla & 12 & 80.700 & 0.291 & $0.563 \pm 0.025$ & $0.580 \pm 0.000$ & -0.042 \\
Saanen & 24 & 92.200 & 0.311 & $0.559 \pm 0.019$ & $0.573 \pm 0.001$ & -0.034 \\
& & & & & &
\end{tabular}
lowest observed heterozygosity $\left(\mathrm{H}_{\mathrm{o}}=0.558 \pm 0.026\right)$ while Toggenburg had the highest $\left(\mathrm{H}_{\mathrm{o}}=\right.$ 


\section{Population structure analysis}

198 Principal components analysis was used to cluster goats and explore the association among 199 individuals and genotype groups. In Fig 2, the principal component, Eigenvector 1 (EV1) which 200 accounts for $15.2 \%$ of the total variance separated the various goat genotypes into differentiated 201 clusters. The second principal component (EV2) accounts for $14.1 \%$ of the total variance, splitted 202 the goat genotypes into four clusters (Alpine, Saanen, Galla and Toggenburg clusters). One outlier, was, however, observed for the Saanen population mixing with Alpine population.

Fig 2. Principal components analyses plot based on SNP array data of goat genotypes

To examine admixture between the genotypes, model-based clustering was performed and the true ADMIXTURE cross-validation $(\mathrm{CV})$ procedure. The $\mathrm{K}$-value with the lowest $\mathrm{CV}$ error was $\mathrm{K}=4$ and was selected as an optimal number of ancestral populations (Fig 3).

214 Population structure plot (Fig 4) showed proportions of ancestral populations for every genotype

215 (Alpine, Galla, Saanen and Toggenburg) for $K=2$ to $K=4$. At $K=2$, Galla goats were separated 
216 from the other three goat genotypes (Toggenburg, Saanen and Alpine) Moreover, Galla goats

217 largely do not carry ancestral components present in Saanen, Alpine and Toggenburg goats (shown

218 in light blue, Fig 4). At K = 3, Alpine and Saanen goats carry ancestral components largely absent

219 from either the Galla or Toggenburg goats. This most likely reveals the past genetic contribution

220 of a breed that has not been included in this study. At $\mathrm{K}=4$, it revealed that Galla had the least

221 level of admixture, whereas, Toggenburg, Alpine and Saanen demonstrated some signs of 222 admixture with Galla.

Fig 4. Population structure plots showing proportions of ancestral populations for every

individual (Alpine, Galla, Saanen and Toggenburg (Toggs) for $K=2$ to $K=4$ ]

The proportions of individuals in each of the genotype in the four most likely clusters estimated by the ADMIXTURE as shown in Table 3 correspond to the four genotypes included in Figs 2 and of Galla were assigned to cluster two with $97 \%$ of its genome assigned to cluster three, five percent

$231(5 \%)$ of Saanen were in cluster three with $84 \%$ of its genome assigned to cluster two. On the other

232 hand, $78 \%$ of Toggenburg was assigned to cluster four with three percent $(3 \%)$ of its genome 233 allocated to cluster one. 
Diagonal indicate inferred cluster.

\begin{tabular}{llllll}
\hline & $\mathrm{N}$ & 1 & 2 & 3 & 4 \\
\hline Alpine & 28 & $\mathbf{0 . 7 0 8} \pm \mathbf{0 . 1 9 7}$ & $0.101 \pm 0.071$ & $0.136 \pm 0.128$ & $0.055 \pm 0.048$ \\
Galla & 12 & $0.020 \pm 0.008$ & $\mathbf{0 . 0 0 8} \pm \mathbf{0 . 0 1 3}$ & $0.970 \pm 0.044$ & $0.009 \pm 0.015$ \\
Saanen & 24 & $0.073 \pm 0.095$ & $0.838 \pm 0.149$ & $\mathbf{0 . 0 4 9} \pm \mathbf{0 . 0 7 3}$ & $0.040 \pm 0.039$ \\
Toggenburg & 30 & $0.030 \pm 0.047$ & $0.015 \pm 0.019$ & $0.173 \pm 0.142$ & $\mathbf{0 . 7 8 2} \pm \mathbf{0 . 1 9 3}$
\end{tabular}

\begin{tabular}{llllll}
\hline & $\mathrm{N}$ & 1 & 2 & 3 & 4 \\
\hline Alpine & 28 & $\mathbf{0 . 7 0 8} \pm \mathbf{0 . 1 9 7}$ & $0.101 \pm 0.071$ & $0.136 \pm 0.128$ & $0.055 \pm 0.048$ \\
Galla & 12 & $0.020 \pm 0.008$ & $\mathbf{0 . 0 0 8} \pm \mathbf{0 . 0 1 3}$ & $0.970 \pm 0.044$ & $0.009 \pm 0.015$ \\
Saanen & 24 & $0.073 \pm 0.095$ & $0.838 \pm 0.149$ & $\mathbf{0 . 0 4 9} \pm \mathbf{0 . 0 7 3}$ & $0.040 \pm 0.039$ \\
Toggenburg & 30 & $0.030 \pm 0.047$ & $0.015 \pm 0.019$ & $0.173 \pm 0.142$ & $\mathbf{0 . 7 8 2} \pm \mathbf{0 . 1 9 3}$
\end{tabular}

238 Genotype relationships were evaluated by computing the genetic distance between all pairwise

239 combinations of individuals (D) from the average proportion of allele shared. Based on the 240 calculated Reynolds genetic distances, a phylogenetic tree was constructed to represent genotype 241 clustering (Fig 5). Population fitting to the same genotype clustered together as inferred by the 242 identity by state (IBS) distance. The results revealed four distinctive clusters: Alpine, Galla, 243 Saanen and Toggenburg (Toggs). This also confirms the results of the principal component and 244 ADMIXTURE analysis. 


\section{Genetic diversity}

252

253

254

255

256

257

258

259

260

261

262

263

264

265

266

267

268

269

270

271

Livestock has been exposed to various forces that contributed to the genetic diversity underlying phenotypic dissimilarities ever since domestication. These forces include; natural selection, artificial selection for specific traits, migration, genetic drift and inbreeding [23, 38]. In Kenya, Toggenburg, Saanen and Alpine were imported to crossbreed with the local goats [Galla and small East African] to improve the milk productivity of local goats under various production systems. They were kept in different geographical locations as isolated populations and subjected to separate breeding objectives for some decades. With the availability of genomic technology, the next step was to investigate genetic diversity and relationships of the different populations/genotypes.

Genotyping with GoatSNP50 Bead Chip revealed some levels of diversity within the goat genotypes in this study. In each genotype, less than $80 \%$ of SNPs exhibited polymorphism, and gene diversity ranged from 0.558 to 0.580 (Table 2). A large number of polymorphic SNPs were detected for Alpine and Saanen genotypes; this was expected because sequenced data from Alpine and Saanen were included in the 50K SNPs panel discovery [31]. Other results using the different number of samples and goat breeds showed $>93 \%$ of polymorphism $[39,40]$. It is, however, very difficult to compare and conclude on the estimates of SNPs stated as polymorphic by other authors because the number of samples genotyped per breed and proportion of genotyped samples used for SNP discovery varied.

The diversity amongst the four genotypes showed Galla had the lowest polymorphism in comparison with the other genotypes. The polymorphic variance is dependent on the history of 
272

273

274

275

276

277

278

279

280

281

282

283

284

285

286

287

288

289

290

291

292

293

294

each genotype. Apart from Galla goats, the other three genotypes were as a result of crossbreeding with local goats (Galla and small East African). Therefore, each genotype may contain genetic contributions from various breeds, thus revealing high polymorphism than Galla goats. In contrast, Galla goats were sampled from the Government breeding station with reputable pedigree records but still maintained levels of diversity $\left(\mathrm{P}_{\mathrm{N}}=81 \%\right)$. This means that genetic evolution can be expected to continue and no fear of inbreeding if selection pressure for target traits is maintained. Additionally, genetic variation to a population allows some individuals to adapt to the environment whereas the continuous existence of individuals is maintained. Inbreeding coefficient observes the probability that the alleles have come from a common ancestor. The negative inbreeding coefficient values in the four genotypes indicated limited inbreeding. It could also mean in this study that many heterozygotes were observed although the sample size for the four genotypes was small.

The observed heterozygosity was lower than the expected heterozygosity $\left(H_{o}<H_{e}\right)$ in the three genotypes apart from Toggenburg which recorded the same value for both observed and expected heterozygosity. The difference between the observed and expected heterozygosity was small which may not be due to inbreeding but a Wahlund effect. The observed heterozygosity in the current study is from a sample of individuals gotten from a structured population even though all subdivisions are in Hardy-Weinberg equilibrium. Over and above the semi and intensive production systems practised by smallholders, there is the presence of artificial selection, gene flow and non-random mating hence not holding the law of HWE in these populations. In this study the observed and expected heterozygosity for Alpine $\left(H_{o}=0.558 ; H_{e}=0.564\right)$, Saanen $\left(H_{o}=0.559\right.$; $\left.H_{e}=0.573\right)$ and Toggenburg $\left(H_{o}=0.580 ; H_{e}=0.580\right)$ were higher than those stated in Canada for Alpine $\left(H_{o}=0.385 ; H_{e}=0.388\right)$, Saanen $\left(H_{o}=0.379 ; H \mathrm{e}=0.382\right)$ and Toggenburg $\left(H_{o}=353 ; H_{e}\right.$ 
$295=336)$ [41]. Moreover, Saanen in Italy recorded the same trend as in Canada $\left(H_{o}=0.41 ; H_{e}=0.41\right)$

296

297

298

299

300

301

302

303

304

305

306

307

308

309

310

311

312

313

314

315

316

[42]. Differences in effective population sizes, length of isolation, selection and breeding management practices in the various production system, may be the cause of variances.

Toggenburg and Galla genotypes, had the highest expected heterozygosity. This could be explained by the observed type of crossbreeding program practised by farmers keeping Toggenburg genotypes resulting into an admixed population. On the hand, organized breeding strategies by use of artificial selection is practised for Galla goat under the Government breeding station. This has resulted in genetic variability and lack of inbreeding for the populations.

\section{Population structure and relationship}

Principal component, admixture and phylogenetic tree analysis of population structure confirmed distinctiveness among the goat genotypes (Saanen, Galla, Toggenburg and Alpine) in Kenya. This can be explained by the demographic history of these genotypes that have been reared for a long time in a separate geographic locations. Although goats from each genotype clustered separately, model-based clustering revealed that admixture has occurred and genetic links exist between the genotypes due to crossbreeding program

Saanen goat shared high genetic associations with Galla goat, with $84 \%$ of its genes resulting from Galla goat, although the PCA differentiated the two genotypes into well-separated clusters. The differentiation might be as a result of Saanen genotype having genetic links with other genotypes but, Galla goat is not admixed. Saanen was the most intermixed genotypes in this study with $84 \%$, $7 \%$ and $4 \%$ of its genome derived from Galla, Alpine and Toggenburg respectively. This may be attributed by noting Saanen was introduced in Kenya to crossbreed with Galla goat later than other breeds (Toggenburg and Alpine). From the admixture results, it can be concluded that Saanen goat 
317 has attained the lowest level of crossbreeding in comparison with other genotypes because the

318 highest percentage of its genome has resulted from Galla goat. For example, according to Bett et

319 al [17] Alpine has achieved up to 87.5\% German Alpine blood level which is confirmed in this

320 study the low proportion of Galla $(10 \%)$ in its genome. Due to inadequate technical capacity on

321 the farmers' side on how to manage the rather complex crossbreeding programs, they could not be

322 able to differentiate the change in blood level phenotypically for Saanen crossbred goats since both

323 Saanen and Galla are white in body colour. Additionally, in recent years, it has been noted that

324 some dairy goat breeds have spread to other areas apart from the original entry areas [15, 43]. This

325 is in agreement with what came out from household survey that Saanen farmers have been

326 purchasing Alpine and Toggenburg bucks/does for breeding due to lack of Saanen breeding

327 bucks/does [44].

328 On the other hand, Alpine and Toggenburg goats shared some links with the Galla goat; $10 \%$ and 329 one percent (1\%), respectively. This was expected because Galla goat was used as the founder 330 population for crossbreeding with Saanen, Alpine and Toggenburg breeds $[12,15,45]$.

331 It is worthwhile noting that Toggenburg was the least admixed genotype in this study, this could

332 be because of well-controlled breeding program practised by farmers under Meru Dairy Goat 333 Breeders Association of Kenya (MDGBA). Members of the association are only allowed to use 334 buck for breeding that belongs to the association. 


\section{Conclusion and recommendations}

338 The study revealed some levels of genetic diversity between goat genotypes in Kenya. Clear 339 genetic divergence between goats in this study was identified which suggested distinct genetic 340 resources in goat genotypes that should be sustainably utilized and conserved. The results also 341 discovered that, there is gene-flow from exotic goats (Alpine, Toggenburg and Saanen) to the Galla 342 populations due to crossbreeding program practised resulting in admixed goat genotypes. It is 343 important to strengthen the various dairy goat breeders associations because urgent management 344 efforts are essential to improve productivity, utilize and conserve the various goat genetic 345 resources. The information generated from this study forms the basis for future genetic resource improvement programs in goat genotypes in Kenya.

\section{Acknowledgments}

350 The authors wish to sincerely acknowledge Kenya Agricultural and Livestock Research

351 Organizations (KALRO) for granting the study leave for the first author and the Egerton University

352 (Njoro, Kenya) for providing support to undertake the study. We express our thanks to Dr. Winfred

353 Mutisya and Dr. Ndiritu Nyaga for assisting in collecting the whole blood following FAO (2011)

354 guidelines. We are grateful to Leonard Okutoyi and Angela M'kwenda from KALRO-

355 Biotechnology Kabete for assisting in extraction, performing the quality and quantity

356 measurements on the genomic DNA samples. The dairy goat farmers and Naivasha sheep and goat

357 breeding station for availing their animals for sample collection are importantly honoured. 

reduction in India: findings from the ODI Livelihood Options Project. 2008. developing countries. Animal. 2013;7(s1):3-18. Nations, Rome. 2016;28. for a breeding programme. Tropical animal health and production. 2010;42(5):875-85.

372 6. Mbuku S, Okeyo A, Kosgey I, Kahi A. Optimum crossbreeding systems for goats in low-input 373 livestock production system in Kenya. Small Ruminant Research. 2015;123(1):55-61.

374 7. Ojango J, Audho J, Oyieng E, Recha J, Okeyo A, Kinyangi J, et al. System characteristics and 375 management practices for small ruminant production in "Climate Smart Villages" of Kenya. 376 Animal Genetic Resources/Resources génétiques animales/Recursos genéticos animales. $377 \quad 2016 ; 58: 101-10$. 
378 8. Scarpa R, Ruto ES, Kristjanson P, Radeny M, Drucker AG, Rege JE. Valuing indigenous cattle

379 breeds in Kenya: an empirical comparison of stated and revealed preference value estimates.

380 Ecological Economics. 2003;45(3):409-26.

381 9. Ahuya C, Okeyo A, Murithi F. Productivity of cross-bred goats under smallholder production

382 systems in the Eastern highlands of Kenya1. Small stock in development. 2005:54.

383 10. Krause A-K. Breeding programmes for small ruminants in the tropics with special reference

384 to the crossbreeding programme of the Dairy Goat Association of Kenya (DGAK) 2006.

11. Bett R, Kosgey I, Bebe B, Kahi A. Breeding goals for the Kenya Dual Purpose goat. II.

386 Estimation of economic values for production and functional traits. Tropical animal health and

387 production. 2007;39(7):467-75.

12. Peacock C, Ahuya C, Ojango J, Okeyo A. Practical crossbreeding for improved livelihoods in developing countries: the FARM Africa goat project. Livestock Science. 2011;136(1):38-44. systems in Kenya: Köster; 2009. smallholder production systems of the eastern highlands of Kenya. Small Ruminant Research. 2009;83(1):7-13. milk production in Nyeri Region. Journal of Food Research. 2014;3(6):160-7.

397 16. Aziz MA. Present status of the world goat populations and their productivity. World. 2010;45(1078.2):1. 

2011;96(1):16-24.

403 production systems: Technical and infrastructural issues. Small Ruminant Research. $404 \quad 2007 ; 70(1): 76-88$.

19. Qanbari S, Simianer H. Mapping signatures of positive selection in the genome of livestock.

20. FAO. Guideline for phenotypical characterisation. 2011. In: Animal genetics training resource, version 3, 2011. International Livestock Research Institute,

412 Nairobi, Kenya, and Swedish University of Agricultural Sciences, Uppsala, Sweden. 2011.

413 23. Groeneveld L, Lenstra J, Eding H, Toro M, Scherf B, Pilling D, et al. Genetic diversity in farm 414 animals-a review. Animal Genetics. 2010; 41(s1):6-31.

415 24. Hoshino AA, Bravo JP, Nobile PM, Morelli KA. Microsatellites as tools for genetic diversity 416 analysis. Genetic diversity in microorganisms: InTech; 2012.

417 25. FAO. Molecular genetic characterization of animal genetic resources. FAO Animal Production 418 and Health Guidelines. 2011. 
419 26. Jarne P, Lagoda PJ. Microsatellites, from molecules to populations and back. Trends in ecology

420 \& evolution. 1996; 11(10):424-9.

421 27. Anmarkrud JA, Kleven O, Bachmann L, Lifjeld JT. Microsatellite evolution: Mutations, 422 sequence variation, and homoplasy in the hypervariable avian microsatellite locus HrU10. BMC 423 Evolutionary Biology. 2008; 8(1):138.

424 28. Weising K, Nybom H, Pfenninger M, Wolff K, Kahl G. DNA fingerprinting in plants: 425 principles, methods, and applications: CRC press; 2005. markers and their use in animal genetics. Genetics Selection Evolution. 2002; 34(3):275.

429 Trends in ecology \& evolution. 2006;21(11):629-37.

430 31. Tosser-Klopp G, Bardou P, Bouchez O, Cabau C, Crooijmans R, Dong Y, et al. Design and 431 characterization of a 52K SNP chip for goats. PloS one. 2014;9(1):e86227.

432 32. Ajmone-Marsan P, Colli L, Han JL, Achilli A, Lancioni H, Joost S, et al. The characterization 433 of goat genetic diversity: Towards a genomic approach. Small Ruminant Research. 2014; 434 121(1):58-72.

435 33. FAO. Phenotypic characterization of animal genetic resources.FAO Animal Production and 436 Health Guidelines No. 11. Rome. Italy. f.pdf http://www.fao.org/docrep/015/i2686e/i2686e00.pdf. 4372012. 

set for whole-genome association and population-based linkage analyses. The American Journal of Human Genetics. 2007;81(3):559-75.

441 35. Zheng X, Levine D, Shen J, Gogarten SM, Laurie C, Weir BS. A high-performance computing

442 toolset for relatedness and principal component analysis of SNP data. Bioinformatics. 2012;28(24):3326-8.

444 36. Alexander DH, Novembre J, Lange K. Fast model-based estimation of ancestry in unrelated 445 individuals. Genome research. 2009;19(9):1655-64.

446 37. Letunic I, Bork P. Interactive Tree Of Life (iTOL) v4: recent updates and new developments.

447 Nucleic acids research. 2019;47(W1):W256-W9.

448 38. Andersson L, Georges M. Domestic-animal genomics: deciphering the genetics of complex 449 traits. Nature Reviews Genetics. 2004;5(3):202-12.

450 39. Visser C, Lashmar SF, Van Marle-Köster E, Poli MA, Allain D. Genetic diversity and 451 population structure in South African, French and Argentinian Angora goats from genome-wide 452 SNP data. PloS one. 2016;11(5).

453 40. Onzima R, Upadhyay M, Mukiibi R, Kanis E, Groenen M, Crooijmans R. Genome-wide 454 population structure and admixture analysis reveals weak differentiation among Ugandan goat 455 breeds. Animal genetics. 2018;49(1):59-70.

456 41. Brito LF, Kijas JW, Ventura RV, Sargolzaei M, Porto-Neto LR, Cánovas A, et al. Genetic 457 diversity and signatures of selection in various goat breeds revealed by genome-wide SNP 458 markers. BMC genomics. 2017;18(1):229. 
459 42. Nicoloso L, Bomba L, Colli L, Negrini R, Milanesi M, Mazza R, et al. Genetic diversity of

460 Italian goat breeds assessed with a medium-density SNP chip. Genet Sel Evol. 2015;47:62.

461 43. Peacock $\mathrm{C}$. The goats model. A proven approach to reducing poverty among smallholder

462 farmers in Africa by developing profitable goat enterprises and sustainable support services. Farm-

463 Africa working paper. 2007;9.

464 44. Waineina RW, Ngeno, K., Okeno, T.O. and Ilatsia, E.D. Performance of Dairy Goat Genotypes

465 in different Production Systems in Kenya. In Proceedings of the Tanzania Society of Animal

466 Production (TSAP), 42nd Scientific Conference, Dodoma, Tanzania 23rd-25th October. 2019.

467 45. Shivairo R, Matofari J, Muleke C, Migwi P, Lugairi E. Production Challenges and Socio-

468 Economic Impact of Dairy Goat Farming amongst Smallholder Farmers in Kenya. Food Science

469 and Quality Management. 2013;17. 


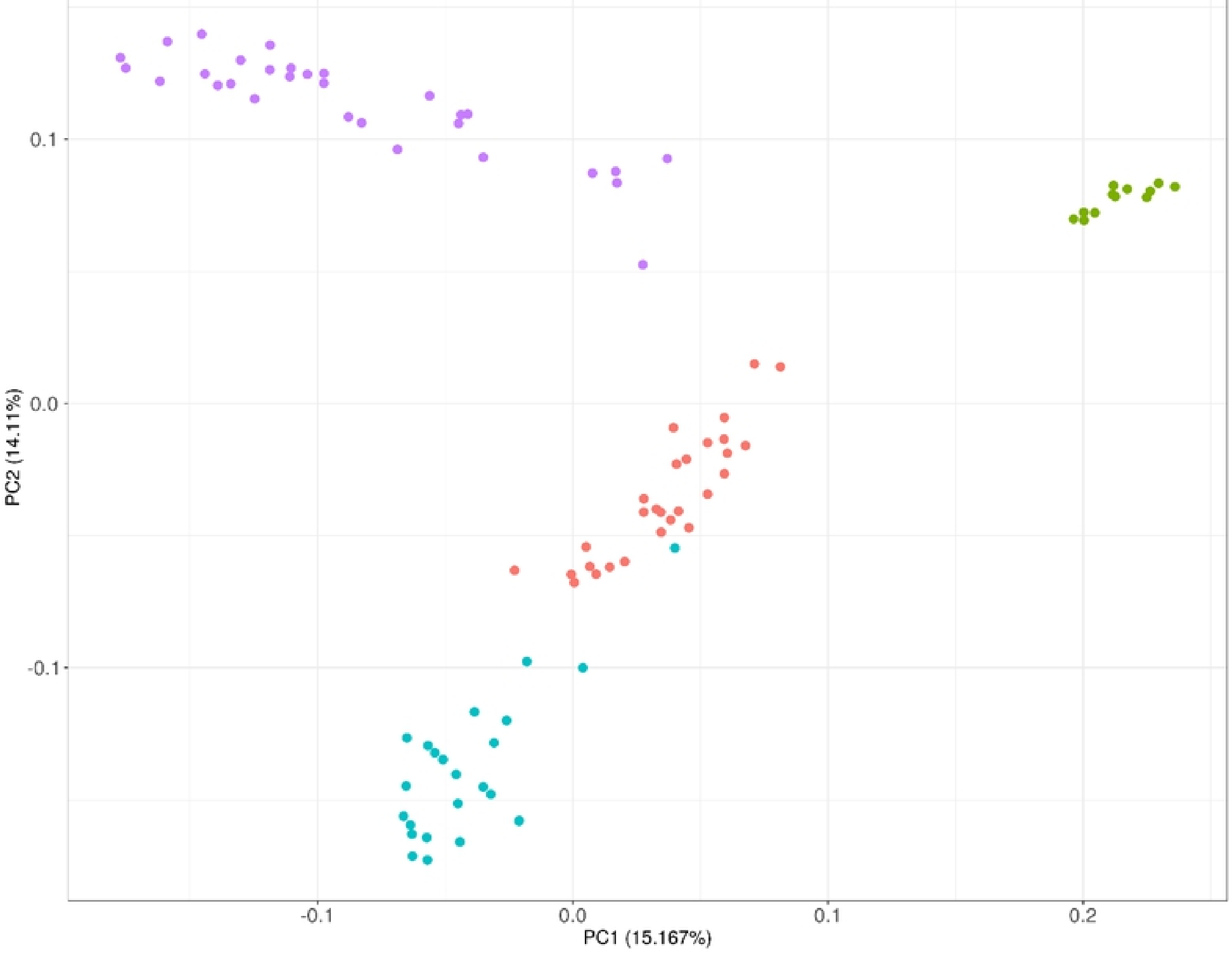

Alpine

Galla

Saanen

- Toggenburg

Figure 


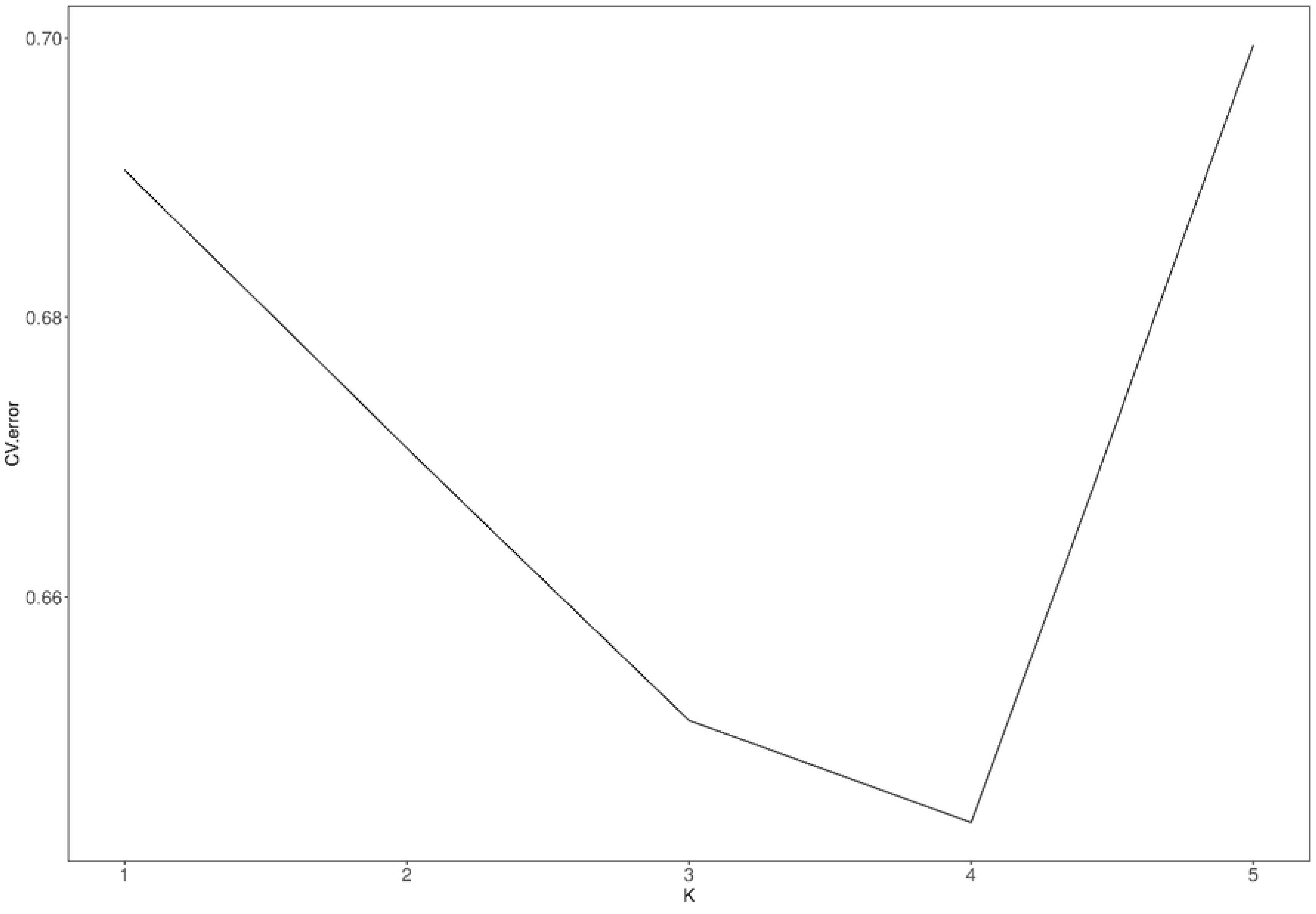

Figure 

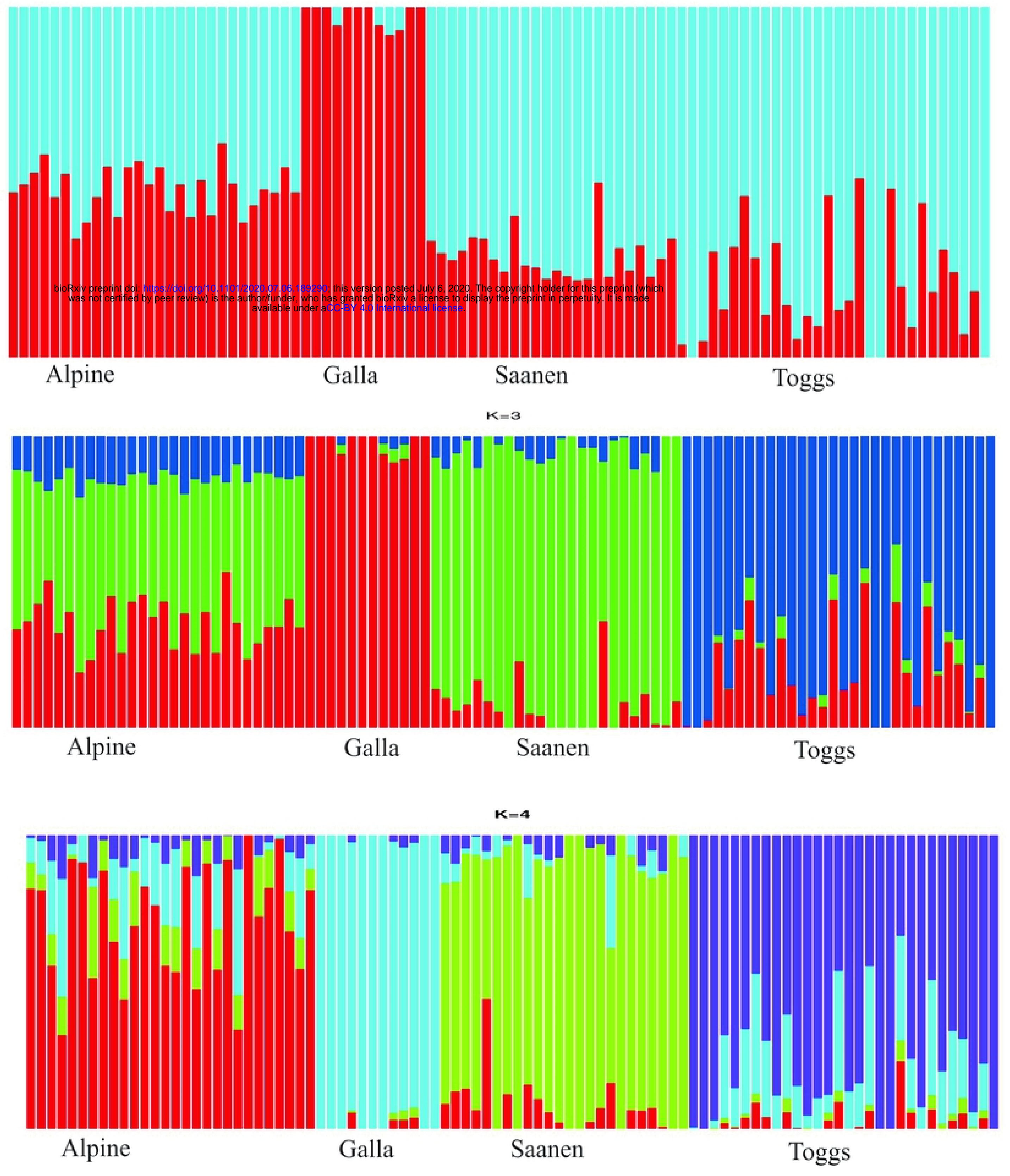

Figure 


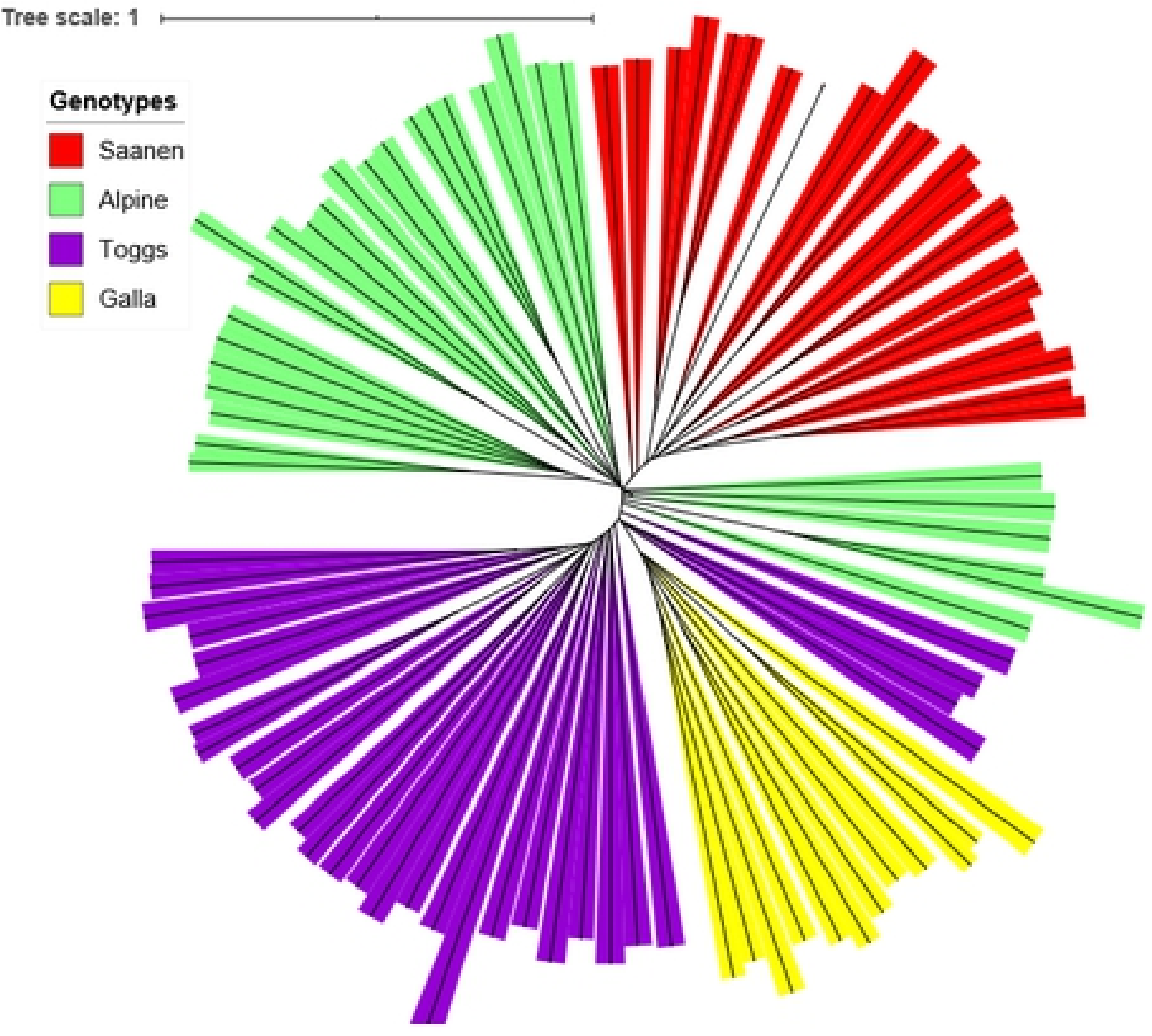

Figure 